\title{
DA NECESSIDADE/ATUALIDADE DA PEDAGOGIA CRÍTICA: CONTRIBUTOS DE PAULO FREIRE
}

\author{
Maria Amélia do Rosário Santoro Franco 1
}

\begin{abstract}
Resumo
O presente artigo discute a epistemologia da Pedagogia Crítica realçando a sua origem nos fundamentos da pedagogia do oprimido de Paulo Freire. Realça a inerência desta racionalidade pedagógica crítica aos processos de reflexividade; dialogicidade e politicidade, bem como discute a incompatibilidade desta racionalidade em espaços/tempos neoliberais. Conclui afirmando a necessidade/atualidade dos princípios pedagógicos críticos junto às práticas educativas, na perspectiva de movimento de resistência à lógica neoliberal.
\end{abstract}

Palavras-chave: Pedagogia; Pedagogia Crítica; Paulo Freire

\begin{abstract}
This article discusses the epistemology of Critical Pedagogy emphasizing its origin in the foundations of Paulo Freire's pedagogy of oppressed. Emphasizes the inherence of this critical pedagogical rationality to the processes of reflexivity; dialogicity and politics, as well as discusses the incompatibility of this rationality in neoliberal spaces / times. It concludes by affirming the necessity / actuality of the critical pedagogical principles next to the educative practices, in perspective of movement of resistance to the neoliberal logic.

Palavras-chave: Pedagogy; Critical Pedagogy; Paulo Freire
\end{abstract}

\section{Resumen}

\footnotetext{
${ }^{1}$ Pedagoga, doutora em Educação; Pós-doutora em Pedagogia. Pesquisadora CNPq; Pesquisadora/professora Universidade Católica de Santos; Pesquisadora GEPEFE-USP. ameliasantoro@uol.com.br Endereço: Rua Campevas 208. Perdizes. São Paulo. CEP: 05016010
} 
En este artículo se analiza la epistemología de la pedagogía crítica destacando sus orígenes en las bases de la pedagogía del oprimido de Paulo Freire. Destaca la racionalidad inherente a estos procesos de reflexividad pedagógicos críticos; la naturaleza dialógica y política, así como analiza la incompatibilidad de la racionalidad en espacios / tiempos neoliberales. Concluye la necesidad / principios pedagógicos críticos actuales con las prácticas educativas en la resistencia a la lógica de movimento em la perspectiva neoliberal.

Palabras-clave: Pedagogía; Pedagogía Crítica; Paulo Freire

\section{INTRODUÇÃo}

Considero ser a criticidade um ingrediente visceral, que estrutura o conceito contemporâneo de Pedagogia, sua identidade e sua lógica. Para mim, a Pedagogia não-crítica deixa de ser Pedagogia e transforma-se em uma tecnologia social, com fins de regulação, dominação, domesticação ou mesmo doutrinação dos sujeitos a ela submetidos. A criticidade permite a relação dialética e formadora entre sujeitos permeados por relações de poder. A ausência desta perspectiva crítica impede a presença de processos dialogais e emancipatórios. Portanto, quando me refiro à pedagogia, como prática social ou como área do conhecimento estou considerando-a necessariamente crítica.

Este texto organiza-se a partir de pesquisas teóricas já realizadas ${ }^{2}$, e teve por foco identificar as condições de surgimento de uma pedagogia crítica, na articulação entre a teoria social crítica e a educação, o que gera uma imensidão de sentidos e perspectivas; no entanto, aqui sigo a orientação de Giroux (1983) e Torres (1980), para afirmar que a pedagogia crítica é um campo diversificado que deveria ser relacionado a trabalhos decorrentes de seu fundador, ou seja, de Paulo Freire.

O que significa dizer que são trabalhos na mesma perspectiva de Freire? Significa, fundamentalmente afirmar que todo trabalho de Freire se constitui como pedagogia crítica, uma vez que sua obra se estrutura em torno de princípios fundantes da lógica da pedagogia crítica, dentre os quais ressalto:

a) A finalidade da educação é formar sujeitos conscientes de seu lugar no mundo; sujeitos que, no processo educativo aprendem a dar nome e sentido ao mundo; jamais sujeitos despersonalizados e objetos à mercê de um processo que lhe é estranho;

\footnotetext{
${ }^{2}$ Especialmente em FRANCO (2001; 2012; 2014); KLAFKI (1986); Habermas (1984); Gentili (1995); Freire $(1976 ; 1984 ; 1999)$.
} 
b) A educação será sempre um ato de resistência à racionalização da prática educativa como pretexto de potencializar o desenvolvimento econômico; a educação jamais poderá se realizar na perspectiva mercadológica;

c) A construção do conhecimento se fará na prática dialógica; na vivência crítica da tensão entre teoria e prática e jamais como transmissão de informações sem vinculação à realidade dos educandos ou dos educadores;

d) A emancipação dos sujeitos da prática deve organizar toda prática pedagógica, num processo contínuo de luta e compromisso social, onde se tecem os fundamentos de uma prática democrática e crítica. Esse processo não se fará, jamais, na perspectiva da doutrinação/domesticação dos sujeitos.

A teoria de Freire esteve, desde sua origem, afinada às teorias sociais críticas de educação europeias e americanas que começavam a emergir nos anos finais do século passado, no entanto, a teoria freireana impregnou e redefiniu a teoria crítica mundial. Uma das razões que pode nos fazer entender o papel de Freire na organização dessa pedagoga crítica, é compreender o lugar social que ele ocupava e o modo como rompeu com a lógica vigente e assumiu criticamente esse seu lugar/tempo histórico.

\section{DA PEdAgogia ClÁSSICA NO BRASIL À PEDAgogia CRÍTICA: O PAPEL DE FREIRE}

Durante todo o período colonial, imperial e mesmo no início do período republicano encontra-se no Brasil a forte presença de uma pedagogia filosófica, utilizada pelos jesuítas, da Companhia de Jesus. A orientação pedagógica dos jesuítas, fundamentada nos princípios da escolástica, era extremamente livresca e autoritária. Fundada na concepção essencialista do homem, pautava-se como prática educativa, pela memorização, pela repetição de exercícios e era totalmente dissociada dos problemas da realidade brasileira. A educação empreendida pelos jesuítas era destinada, especialmente, a dar cultura geral, sem qualquer preocupação com a qualificação ao trabalho, com a pesquisa ou com a qualificação de professores. Era uma pedagogia, que em termos de intencionalidade social, atendia aos anseios de uma sociedade elitista, escravocrata, aristocrática, não podendo, conforme Fernando de Azevedo (1937, p. 24) "contribuir para modificações estruturais na vida social e econômica do Brasil, na época."

Essa influência vai marcar muito a pedagogia brasileira e será aos poucos, um pouco transformada, absorvendo algumas mudanças sócio-culturais-políticas do país e integrando outras tendências, em especial, após 1930, com o Movimento da Escola Nova, no bojo, 
principalmente, do pragmatismo de Dewey e das tendências tecnológicas posteriores, a pedagogia brasileira passa a gravitar em torno da concepção técnico-científica.

Esta concepção vai impregnar bastante a prática pedagógica brasileira e configurar quase que toda estruturação legal-administrativa e pedagógica da organização das escolas e dos cursos de Pedagogia.

Aos poucos, a Pedagogia brasileira foi superando a visão essencialista da natureza humana e incorporando uma concepção mais centrada na questão da existência, da vida e da atividade.

Percebe-se que são influências advindas, quer do pragmatismo de Dewey, quer de uma concepção mais romântica, na linha de Pestalozzi, Fröebel, Bergson e sem esquecer da influência da psicologia experimental, muito presente na realidade brasileira, conforme Anísio (1934).

Significa dizer que outros elementos começam a compor o pensamento de educadores e mais que tudo é importante realçar que a Pedagogia começa a se psicologizar, a se sociologizar, a se biologizar. Deixará de ser vista como ciência unitária, mas também não será vista como ciência integradora.

No bojo deste clima, ou grande produtor deste clima, que é conceitual e político essencialmente, emerge um forte movimento entre educadores brasileiros, com vistas a um processo de renovação das práticas escolares, conhecido como "Manifesto dos Pioneiros da Educação" e teve seu auge, enquanto concepção, em 1932 quando redireciona a epistemologia da pedagogia, no sentido do pragmatismo utilitarista de Dewey.

Este movimento ganha força e chega mesmo a impregnar o espírito da época, com repercussões históricas marcantes, porque, de alguma forma, atendia aos anseios da classe política dominante. Saviani (1983) referenda este ponto de vista ao dizer que a escola era vista como elemento de concretização da política liberal da classe dominante, como a redentora da humanidade, para funcionar como a esperança do povo. À medida que esta escola é percebida pela classe popular como não atendendo a estes anseios, usa-se o argumento, no discurso oficial, de que é preciso reformular a escola. Assim a Escola Nova passa a ter um espaço de atuação e visibilidade, consentido e incentivado pela classe política e classe social dominante. Diz o autor: "a Escola Nova surge, pois, como um mecanismo de recomposição da hegemonia da classe dominante, hegemonia essa ameaçada pela crescente participação política das massas, viabilizada pela alfabetização através da escola universal e gratuita" (SAVIANI, 1983, p. 31). Com o advento do escolanovismo as preocupações educacionais vão abandonar o terreno político/ideológico e se abrigar no âmbito técnico-pedagógico, com isto 
desmobilizando as forças populares, que se organizavam, e servindo de instrumento à manutenção da hegemonia da classe dominante.

Nesta época, década de trinta, do século passado, criam-se escolas profissionalizantes "para os menos favorecidos", configurando, na lei e na prática, mais uma vez a dualidade do sistema educacional brasileiro, ou conforme Freitag (1984, p. 52), ao dizer que a intenção da política educacional da época "é transformar o sistema educacional em um instrumento mais eficaz de manipulação das classes subalternas."

Perde-se neste horizonte instrumental e tecnicista o aspecto fundamental da Pedagogia como reflexão, como orientadora dos espaços educacionais para formação de cidadãos, como crítica de ações educacionais.

É neste contexto que os cursos de Pedagogia são criados, em 1939, com a finalidade de formar o professor formador de docentes, bem como o bacharel, para exercício dos cargos técnicos de educação. Não se pode esquecer que 1939 é um momento político de ditadura brasileira...

A concepção pragmática tecnológica está presente no espírito da lei ${ }^{3}$ que cria este curso: o curso será destinado a formar técnicos e professores, e assim os cursos se organizam na intencionalidade de formar professores organizadores da instrução, operadores de sala de aula. Não houve a intenção de que o curso viesse a configurar um espaço de reflexões, pesquisas, propostas e políticas. E isto será, um fardo e um entrave que os cursos de Pedagogia carregam até hoje!

Nesta década de 60, do século passado, a escola fundamental pública gozava de bastante prestígio junto à burguesia brasileira, principalmente nos Estados mais desenvolvidos da nação, onde a escola pública estava razoavelmente presente.

No entanto, nas regiões mais pobres do Brasil cresciam e aprofundavam problemas relativos ao analfabetismo e à exclusão escolar de grande parcela da população. Nesta época a taxa de analfabetismo girava em torno de $40 \%$ da população, sendo que na região Norte e Nordeste essa taxa chegava a mais de $50 \%$ da população com mais de 15 anos.

É nesse Brasil, impregnado na perspectiva de uma pedagogia tecnicista e liberal; com reminiscências de uma pedagogia essencialista e livresca, um país de extremas desigualdades sociais; com regiões de imensa miséria e pobreza, que se verá emergir uma proposta pedagógica eminentemente emancipatória e crítica: a Pedagogia do Oprimido.

\footnotetext{
${ }^{3}$ Decreto-lei 1190 de 4 de abril de 1939.
} 
Na confluência do contexto político cultural, que antecedeu ao golpe militar de 1964, com a expansão de movimentos educacionais de base e o novo papel exercido pela Igreja Católica, surgiu o importante movimento epistemológico da pedagogia brasileira: A Pedagogia do Oprimido, com Paulo Freire, que carrega as características de uma pedagogia crítico-emancipatória, embora não exclusivamente.

Esta pedagogia vem conferir um novo panorama à epistemologia pedagógica, mesclando diversas concepções filosóficas, carregando uma proposta eminentemente política, não conivente com a da ideologia da classe dominante. Mesmo tendo sido um processo precocemente abortado pelo golpe militar de 1964, suas raízes estavam fincadas, e germinaram em outros espaços e tempos.

Quero realçar que a Pedagogia do Oprimido surge como um rompimento epistemológico e político frente ao que se desenhava como perspectiva política da educação e mais que tudo, surge como uma resistência à lógica liberal e tecnicista que marcava a história política do Brasil até aquele momento.

Em poucas palavras, a pedagogia crítica tem envolvido um esforço complexo, de ligação entre a teoria crítica e as práticas educativas tal como entendidas por Freire: a relação entre reprodução societal e educação; uma sociologia estrutural do currículo; uma compreensão interacionista das atividades da sala de aula e do papel do professor, isso em termos de relações de poder que definem a educação em relação à constituição do pacto democrático de determinadas sociedades. (TORRES; MURROW, 1998 p. 140).

É exatamente esta questão que foi diretamente abordada por Freire: não era apenas uma teoria social crítica; mais que isso, o que ele propunha era uma maneira inevitável, inexorável de ser e estar educador: assumir um papel social a favor dos "esfarrapados da vida" e dar-lhes os instrumentos para tensionar as relações de poder postas historicamente. É nesse ponto que faço o realce: ou é uma pedagogia que se assume com os sujeitos; na luta coletiva por sua emancipação; ou não é pedagogia!

O trabalho pedagógico de Paulo Freire com a educação de adultos, carrega e favorece um grande rompimento epistemológico com a intencionalidade da educação vigente no Brasil. Até então, pressupunha-se a educação como uma forma de encaminhar os educandos à cultura letrada da elite e Paulo Freire recoloca esta situação, no sentido de alertar que a educação tem por finalidade a humanização do próprio homem e deve ser um instrumento que permite ao educando ressignificar sua humanidade, redescobrir seu lugar no mundo, amalgamar-se com sua cultura, dela se fazer um elemento e transformar essa cultura à medida que a apreende e se transforma como elemento da cultura. 
Portanto a educação passa a ser vista não mais como instrumento que deve propiciar a posse de uma cultura estranha e construída por outros, mas um processo de realizar nos educandos a possibilidade de se tornarem homens em plenitude, produtores, interpretadores de cultura e capazes de apreender e construir cultura.

Enfim, a educação se destina a formar homens ou a dotá-los de conhecimentos previamente selecionados e julgados por outros, como sendo os necessários? Essa questão ainda permanecesse em nosso Brasil do século XXI!!!!

Está certo que Paulo Freire não descarta a importância da cultura letrada, no entanto é uma questão de encarar o fenômeno da relação homem mundo de maneira diferente: antes de ser método e técnica de transmissão, a educação deve ser um ato político, que organiza a intencionalidade do ensino, a partir do sujeito, visto sempre em seu coletivo social. Paulo Freire não desconsiderava o papel da informação, mas considerava que as informações de nada servirão se, paralelamente ao ato de conhecer, o sujeito não criar uma "nova teoria do conhecimento" que será a matriz de um novo quadro interpretativo, que irá permitir ao aluno reelaborar seus conhecimentos dentro de uma nova ótica, a ótica do sujeito ${ }^{4}$.

Em 1958, no Congresso Nacional de Educação de Adultos, Freire colocava que o processo educacional da alfabetização de adultos deveria firmar-se na consciência da realidade cotidiana e jamais reduzir-se à leitura de letras e palavras. Sua proposta passa a ser um grande divisor de águas frente a uma educação que ao se tecnificar, supunha-se neutra, mas era opressiva e elitista e servia para a manutenção das tradições arcaicas e discriminatórias, secularmente vigentes no país.

Assim, frente ao peso do ensino verbalista decorrente dos estudos de Herbart, ele propõe uma teoria do conhecimento que será a mediação entre sujeito e cultura; frente ao ativismo da escola deweyana, ele vai propor uma ação transformadora do sujeito e da realidade; frente à histórica separação entre teoria e prática, sempre reafirmada pelos teóricos positivistas, ele proporá a práxis; frente às aulas dirigidas por discursos e narrativas, ele sugerirá o diálogo; frente ao conformismo e adaptação ao social, ele proporá a conscientização; contra a pedagogia do colonizador que instrumentaliza os alunos para bem servirem ao sistema, ele propõe a pedagogia do oprimido, fazendo do aluno um sujeito histórico.

\footnotetext{
${ }^{4}$ Vejo muita similaridade deste conceito de Paulo Freire com a atual proposta de Charlot (2000) quando se refere ao fato de que o sujeito, aluno, precisa construir novas relações com o saber, de forma que o conhecimento tenha sentido ao sujeito.
} 
Torres (1979), no prefácio, assim coloca sua posição em relação à pedagogia do oprimido: é uma pedagogia científica em que a dimensão epistemológica se congrega com a dimensão gnosiológica para fundamentar uma antropologia política que revaloriza dois instantes cruciais do acontecer social contemporâneo: a consciência e a história.

O pensamento de Paulo Freire carrega diversas nuances de variadas tendências filosóficas. Ele próprio diz: "minha perspectiva é dialética e fenomenológica”, porém seu próprio pensamento sofre evoluções que são hoje bastante analisadas no cenário mundial. $\mathrm{O}$ próprio Torres diz que três filosofias marcaram sucessivamente a obra de Freire: o existencialismo, a fenomenologia e o marxismo, realçando que a dialética hegeliana está presente em quase toda a obra de Freire.

Heinz-Peter Gerhardt (1996, p.163) assim se expressa sobre os fundamentos epistemológicos do trabalho de Freire:

O sistema educacional e a filosofia da educação de Freire tem suas referências numa miríade de correntes filosóficas, tais como fenomenologia, existencialismo, personalismo cristão, marxismo humanista e hegelianismo, cujo detalhado enfoque ultrapassaria os limites deste perfil.

Schmied-Kowarzik (1983, p. 69) escreve que Freire, ao entrelaçar temas cristãos e marxistas, retoma a relação originária entre dialética e diálogo, definindo a educação como a experiência dialética da libertação humana. "Desta forma ele vincula de um modo fecundo a própria dialética de Litt, referida à respectiva situação educacional concreta, com a determinação dialética da educação em Kant, como experiência histórica da totalidade da sociedade."

A obra de Freire no Brasil foi bruscamente interrompida ${ }^{5}$, mas teve diversas continuidades no mundo, demonstrando sua pertinência como fundamento de uma pedagogia que aliando ciência, arte e política, influenciou outras áreas do saber e apresentou diretrizes que foram profundamente utilizadas por vários trabalhadores sociais em suas práticas: filósofos, terapeutas, médicos, cientistas. Sua obra prenunciou um tratamento interdisciplinar das ciências, enriquecendo o trabalho de educadores com novas formas de pesquisa, como a pesquisa participante, demonstrando que a Pedagogia pode ser uma ciência articuladora de saberes e também instrumento fundamental, essencial, à emancipação da humanidade.

Freire, em seu último trabalho, "A Pedagogia da Autonomia", realça a questão dos saberes necessários à prática educativa, que extrapolando os saberes já cristalizados, podem,

\footnotetext{
${ }^{5}$ Sua obra foi interrompida logo após o golpe militar de 1964 , que instituiu mais uma vez a ditadura militar em nosso país.
} 
via um trabalho reflexivo e transformador, redundar numa leitura crítica das condições de degradação da humanidade, e assim fundamentar as condições de um saber fazer crítico e emancipatório que, alicerçado no desejo e na alegria, mas sem abrir mão do rigor, da seriedade e simplicidade do fazer competente, poderá redirecionar os descaminhos tomados pela humanidade em relação à construção da dignidade humana.

\subsection{Teoria social crítica e pedagogia crítica}

Muitas vezes tive que explicar a pesquisadores iniciantes que nem toda teoria social crítica corporificou-se em uma pedagogia crítica. Há teorias sociais críticas que provêm da sociologia; da filosofia ou mesmo da antropologia ou da própria pedagogia que subsidiaram perspectivas críticas à pedagogia, mas não se corporificaram em uma pedagogia crítica. Considero que as teorias da educação modulam referenciais para configuração de processos de formação humana, cabendo à Pedagogia, como ciência da práxis educativa (da/para a educação), organizar, avaliar e perseguir, práticas que permitam a busca de compreensão teórica e prática desses processos educativos-formativos.

Paulo Freire foi aquele que incorporando teorias sociais críticas que compuseram sua formação, criou a Pedagogia Crítica, como conceito e como práxis. Ele foi o autor de uma prática que consolida uma teoria e de uma teoria que se retifica e se robustece com a prática.

A teoria crítica da educação e a pedagogia crítica, referem-se a determinadas formas de pensar o ato educativo e de organizar a prática educativa concreta (LIBÂNEO, 1998), considerando que as articulações entre a educação e a sociedade devem se compor por meio de problematização permanente. Neste sentido, a pedagogia crítica diz respeito à teoria e à prática do processo de formação humana que compreende não só a apropriação de conhecimentos, mas a construção de ideias, conceitos, valores, atitudes para a emancipação dos sujeitos e a transformação das relações de dominação nas sociedades desiguais.

A necessidade da Pedagogia crítica se impõe devido às grandes desigualdades sociais que caracterizam a sociedade brasileira. Assim, essa Pedagogia parte da crítica da sociedade injusta e desigual e do papel da educação como instrumento de democracia social, propondo a educação como instrumento de transformação das condições opressoras. Nesta perspectiva crítica, estão abrigadas propostas pedagógicas que orientam ações educativas que devem contribuir para a formação crítica dos sujeitos através de processos reflexivos de discussão, compreensão e ação transformadora das relações sociais de dominação. A ênfase na crítica da 
organização da sociedade desigual e no papel crítico e transformador da educação tem como fundamento teórico a teoria marxista.

Considero que a Marx e Engels compõem o pano de fundo da Pedagogia Crítica proposta por Freire, uma vez que a partir deles consolidou-se a ideia de que as formas de concretização da educação emergem da realidade socioeconômica e da luta de classe que caracteriza e sustenta essa mesma realidade. A partir de Freire não mais caberá à Pedagogia ser uma atividade neutra, mas será necessariamente uma prática que absorve em seu fazer social a dialeticidade da realidade sociohistórica, conforme bases teóricas lançadas por Marx e Engels e atualizada como práxis pedagógica em Freire.

Desta forma, após a Pedagogia do Oprimido e demais trabalhos de Freire, pelo menos, duas considerações estruturam a prática pedagógica:

a) A prática pedagógica precisa absorver o complexo sentido da dialética da práxis social: A prática que nega a práxis, nega o sentido partilhado da vida coletiva; nega desconsidera as circunstâncias do tempo histórico. Schmied-Kowarzik (1984, p.43) considera que esta é a grande revolução teórica provinda de Marx, e reafirmada por Freire, ou seja, a de reconhecer na práxis social o fundamento de todo desenvolvimento histórico, alertando para o fato de que os homens não podem se realizar como produtores de suas condições de vida, mas inversamente, que as condições de vida, ou seja," as imposições de fato das condições de produção, o poder político e jurídico das relações de dominação, a capacidade enganadora da ideologia - determinam os homens em sua atividade a partir do exterior, como estranhos."

Cabe esclarecer, como o faz Kosik (1995, p.222), que quando falamos em práxis no sentido do materialismo histórico não podemos estar nos referindo a uma atividade prática que se contrapõe, ou se complementa, ou que se instala ao lado ou contraposta à teoria. A práxis a partir de Marx e reafirmada por Freire, é a certeza do homem como produtor de sua realidade social, portanto o único que pode compreendê-la. Portanto a práxis é ativa, “é atividade que se produz historicamente, quer dizer, que se renova continuamente e se constitui praticamente - unidade do homem e do mundo, da matéria e do espírito, de sujeito e objeto, do produto e da produtividade."

b) A Pedagogia passa a assumir uma função essencialmente política e uma epistemologia essencialmente fundada na dialética: Para a Pedagogia, a partir da compreensão desse significado de práxis, decorre uma transformação radical em sua posição como ciência da sociedade, eminentemente política, e essencialmente dialética, quer na construção de sua epistemologia, quer no seu exercício como ciência, na construção de seu objeto e na realização de sua prática. A Pedagogia será aquela prática social que se destina à formação de 
indivíduos inseridos na práxis social, conscientes de seu papel na construção da realidade, entendido como domínio da natureza e como exercício de liberdade, concomitantemente.

Esta tarefa, de formar indivíduos na e para a práxis, conscientes de seu papel na conformação e transformação da realidade sociohistórica, exige um trabalho educacional crítico, que pressupõe sempre uma ação coletiva através da qual os indivíduos tomarão consciência do que é possível e necessário, a cada um, na formação e controle da constituição do modo coletivo de vida. A essência desta tarefa é eminentemente política, social e emancipatória.

Paulo Freire organizou uma Pedagogia que dá conta de uma teoria. A prática desta Pedagogia, ao se consolidar absorveu e foi absorvida por outras teorias que à época emergiam (décadas finais do século passado). Essa é a questão crucial que estou afirmando nesse artigo.

As ampliações posteriores do pensamento de Marx, por outros pesquisadores, deram à Pedagogia, amplas e frutíferas contribuições. Pode-se lembrar de Bourdieu e Passeron (1975), que partindo da análise crítica da sociedade capitalista na França, alertam para a questão da reprodução social, ou seja, para além da reprodução da cultura, há a reprodução dos significados ideológicos da cultura e as instituições escolares teriam a função de perpetuar a própria estrutura social hierarquizada, com os significados elaborados pela classe dominante, fazendo com que o sistema educacional, ao transmitir a cultura de poder e privilégios da classe dominante, camufle esta função sob uma aparência de neutralidade, de apoliticidade, reproduzindo como cultura universal, a ideologia da classe dominante. O impacto desta análise dos autores é grande, uma vez que irá redirecionar, entre outras coisas, o sentido de educação popular, contribuir para uma reinterpretação da questão do fracasso escolar, introduzir um olhar mais crítico na questão da organização dos currículos e produzir outras teorias que expandem e aprofundam essa questão. A Pedagogia do Oprimido é uma luz para reinterpretação da teoria da reprodução social.

Seguiram-se muitos outros estudos que procuraram dar continuidade a esta interpretação da dinâmica de funcionamento dos sistemas sociais. Desses estudos realço Althusser (1970); Baudelot e Estabelet (1971), que procuram identificar os verdadeiros mecanismos que produzem e mantém as estruturas de desigualdade social mantidas e perpetuadas sob a aparência de igualdade e semelhança. É fundamental a análise que Althusser faz caracterizando a escola como aparelho ideológico do estado (AIE).

Poulantzas e Estabelet analisam que a escola e outras instituições de socialização, na realidade, não criam a divisão em classes, mas contribuem para ela e a reproduzem. A escola 
seria um mecanismo de reforço da própria relação capitalista. Ou como escreve Freitag (1984, p. 34):

\begin{abstract}
Assim a escola, na medida em que qualifica os indivíduos para o trabalho, inculcalhes uma certa ideologia que os faz aceitar sua condição de classe, sujeitando-os ao mesmo tempo ao esquema de dominação vigente [...] ou mais adiante: é pois a escola que transmite as formas de justificação da divisão de trabalho vigente, levando os indivíduos a aceitarem, com docilidade, sua condição de explorados, ou a adquirirem o instrumental necessário para exploração da classe dominada.
\end{abstract}

Outra grande contribuição, decorrente deste eixo marxista do papel da escola, da sociedade, e da Pedagogia, é a de Gramsci, que repensa os princípios metodológicos do marxismo e oferece à luta de classes um papel emancipatório.

Gramsci revendo a teoria marxista, interpreta que é possível transformar a realidade através da construção de um novo partido (revolucionário e proletariado), que construa uma hegemonia cultural que, na ação se transforma em hegemonia política, e, desta forma, possa ir minando a ideologia da classe dominante.

Como se percebe, o papel da Pedagogia é fundamental em Gramsci, pois a hegemonia cultural se constrói na ação educativa, de várias instituições sociais que educam no amplo sentido, formando os "intelectuais orgânicos", e produzindo uma profunda mediação entre cultura e consciência crítica.

Gramsci será, conforme Freitag (1984), o autor que atribui à escola e a outras instituições da sociedade civil (aos AIE de Althusser), a dupla função dialética e estratégica de conservar e minar as estruturas capitalistas. Desta forma, seus estudos favorecem a entrada em cena de uma Pedagogia do Oprimido e permitem ainda a organização institucional do processo emancipatório, à medida que a contra ideologia se constrói e faz circular, ao lado da cultura dominante, uma nova concepção de mundo e educação, produzindo, evidenciando e tornando pedagógicas as contradições aí imanentes.

É por isto que Gramsci (1973) considera que toda relação de hegemonia é sempre uma relação pedagógica, e isto confere à educação um papel eminentemente político, uma vez que o controle da circulação das hegemonias, nos sistemas educacionais, será sempre um fator decisivo nas mediações das forças presentes na luta de classes.

A teoria de Gramsci reforça e reafirma a Pedagogia do Oprimido ao realçar o caráter eminentemente político, de reorganizar, através de uma pedagogia que carregue o interesse dos oprimidos, a contra-ideologia. A contra ideologia terá a função de divulgar uma nova concepção de mundo, sob a ótica dos excluídos do raio de cobertura da classe dominante. 
Assim, corroendo, destruindo, dando novas interpretações à cultura hegemônica da classe dominante, poderá abrir espaços para um processo emancipatório, que implicará um novo jogo de forças na luta de classes. Esse processo dialético e revolucionário poderá ser semente de transformações históricas, que podem conduzir a um mundo com mais inclusões, igualdade e possibilidades de convivência humana.

A partir especialmente de Marx, Gramsci e Freire pode-se construir a grande utopia revolucionária da Pedagogia, de acreditar que será possível transformar o mundo através da transformação das consciências, e esta tarefa se fará através de um trabalho pedagógico comprometido com as classes populares e com a construção de uma sociedade mais justa.

Realça-se aqui o trabalho de educadores como intelectuais orgânicos, responsáveis pela reelaboração e distribuição da ideologia da classe dominante e dos pedagogos como intelectuais críticos, na recondução e reorganização da classe dos educadores em torno da utopia de reconstrução da sociedade.

Gostaria de realçar também, não como decorrência direta, mas como um "desvio aproximativo" do marxismo, mesclado com novas influências, o movimento da pedagogia cristã, centrado no Personalismo de Mounier, uma vez que, alguns componentes deste movimento, estarão também presentes na gênese da Pedagogia do Oprimido no Brasil.

Mounier exerce a tentativa de sintetizar alguns pressupostos do existencialismo com os do marxismo, integrando as exigências de responsabilidade pessoal com compromisso político. Sugere uma educação que forme para o comunitário, sem fazer desaparecer a pessoa, ao contrário, realçando-a. Propõe uma pedagogia que induza o homem a "sair para fora de si mesmo" e desenvolver os sentidos de "compreender" o outro; que esteja disponível a assumir o outro, no sentido do compromisso com o comunitário; e de libertação pelo trabalho ao outro, ao coletivo. $\mathrm{O}$ autor concorda com Marx sobre o valor do trabalho afirmando que: "O valor central que assume em Marx a atividade prática do homem (práxis) é uma espécie de laicização do valor central que o trabalho assume na tradição cristã”. Para a seguir afirmar que: "as relações entre a pessoa e a natureza não são, pois, relações de pura exteriorização, mas relações dialéticas de permuta e ascensão" (Mounier, 1964, p. 54).

Considero que a partir do personalismo, a ação pedagógica e ação social se aproximam e se confundem; assim como a participação social e a participação educativa se encontram em torno do eixo do pedagógico e se concretizam na teoria e prática da Pedagogia do Oprimido, marco das pedagogias críticas no mundo. Nesta perspectiva há que se realçar que Freire, em sua Pedagogia do Oprimido, faz uma síntese integradora de concepções anteriores, firmando a 
perspectiva de uma pedagogia que articula, de modo visceral, o método com os valores e intencionalidades de uma práxis social, libertadora dos oprimidos, sujeitos da educação.

\subsection{Pedagogia crítica hoje}

A consolidação de políticas neoliberais no Brasil tem produzido tensões incalculáveis na prática da pedagogia, da docência e dos saberes instituídos. Mais do que a reestruturação das esferas econômica, política e social, o que vem à tona é a redefinição e a reelaboração das formas de significar, de representar e de valorar o mundo. Gentili (1995, p.244) realça que "o neoliberalismo precisa, entre outras coisas, despolitizar a educação, dando-lhe significado de mercadoria para garantir o triunfo de suas estratégias mercantilizantes e o necessário consenso em torno delas."

Esta despolitização é uma das principais rupturas que abalam a racionalidade pedagógica (crítica) da educação. Outras existem e se interpenetram. Para reafirmar esse ponto de vista, é sempre bom lembrar de Gentili (1995, p. 244-245):

[...] o neoliberalismo precisa - em primeiro lugar, ainda que não unicamente despolitizar a educação, dando-lhe um novo significado como mercadoria para garantir, assim, o triunfo de suas estratégias mercantilizantes e o necessário consenso em torno delas.

A ciência da educação em sua história já compreendeu que de nada vale oferecer ao educador, teorias sobre fatos e normas observadas que ele professor deva aplicar; mas o fundamental é auxiliar o educador "a perceber as exigências de cada situação educacional concreta, de tal forma que ele se torne apto a levá-las a cabo autonomamente" (SchmiedKowarzik, 1983, p. 50). O que se realça é a necessária formação do professor, do pedagogo, para o pensamento autônomo, crítico, uma vez que, esta posição sobre a reflexão da responsabilidade do educador, deve ser o cerne da ciência pedagógica e que por isto, a prática pedagógica não pode se realizar de forma neutra, sem os compromissos com o sujeito e suas circunstâncias. Considero que toda pedagogia deva transformar-se em uma pedagogia do oprimido, no sentido de trazer o sujeito ao diálogo, à reflexão, ao compromisso com a formação.

Nunca é demais realçar que quando se fala da politicidade das práticas pedagógicas, quer-se realçar que isto não significa a doutrinação pedagógica ou domesticação pedagógica. 
Ao contrário, o pensamento crítico do professor, é a maior arma contra o proselitismo doutrinário. A politicidade exerce-se na perspectiva freireana:

A compreensão dos limites da prática educativa demanda indiscutivelmente a claridade política dos educadores com relação a seu projeto. Demanda que o educador assuma a política de sua prática. Não basta dizer que a educação é um ato político, assim como não basta que o acto político é também educativo. É preciso assumir realmente a política da educação. (FREIRE, 1993, p. 46-47).

Quero realçar a questão da busca da política de sua prática. Essa busca, essa tarefa é eminentemente pedagógica. Como afirma Therrien (2006, p. 77) “a racionalidade pedagógica é inconcebível fora do contexto da epistemologia da prática”. Para em seguida afirmar:

Ela é o suporte de uma práxis educativa como processo de reflexão sistemática sobre a ação por parte de sujeitos, social e coletivamente, voltados para a construção de conhecimentos e saberes que refletem os significados e sentidos num horizonte de transformação do mundo da vida com emancipação social.

É essa a politicidade que é inerente ao ato pedagógico, ou seja, é o professor ciente de seu papel social como educador, sabendo a favor e contra o que está atuando.

Desta forma pode-se perceber o perigo que ronda os processos de ensino quando este se torna excessivamente técnico, planejado e avaliado apenas em seus produtos finais e quando a voz do professor é calada pela fragilidade de sua formação inicial.

Como frisa Kincheloe (1997, p.214) ao relembrar que o professor que trabalha na perspectiva epistemológica crítica e construtivista rejeita modelos que consideram o ensinar "como a provisão de fatos, enquanto adota uma visão que considera o processo como uma reformulação dialógica (...)."

Esta questão dialógica foi talvez o principal conceito articulador da teoria de Freire: ao considerar a práxis como ideia chave que organiza as práticas pedagógicas ele realça que na interação entre educadores e educandos, sujeitos em processo de ensinar e aprender, a problematização e o diálogo são as condições que permitem a emergência de processos libertadores e emancipatórios.

Como nos ensinou Freire, a educação se faz em processo, em diálogos, nas múltiplas contradições que são inexoráveis entre sujeitos e natureza que mutuamente se transformam. Medir apenas resultados e produtos de aprendizagens, como forma de avaliar o ensino, pode se configurar e tem se configurado como uma grande falácia que oprime os sujeitos da educação. 


\section{CONSIDERAÇÕES}

Concluo afirmando que hoje, frente a realidade educacional brasileira, mais que nunca precisamos de uma pedagogia crítica, pautada nos princípios freireanos, de forma a que se criem novos sentidos de participação e envolvimento dos docentes com sua prática e dos discentes com seu trabalho pedagógico.

Precisamos de muitos Paulos Freires que façam o verbo pedagógico transmudar-se em prática pedagógica e que consigam transformar as intenções em gestos e ações que podem transformar a aridez pedagógica do mundo que hoje nos cerca.

Quis realçar neste artigo que a pedagogia requer espaços/tempos críticos para poder atuar na perspectiva que lhe é inerente, qual seja: de formação; de humanização e de emancipação.

Afirmo ser o conceito pedagogia crítica, quase um pleonasmo, ou um mero realce, uma vez que, não ser crítica, tira-lhe a especificidade que a constitui.

Pode-se olhar ao redor: em tempos neoliberais de excessivo controle e regulação das práticas pedagógicas; de excessiva vinculação das práticas educativas à lógica do mercado e de excessivo foco nas práticas de formação ao consumo, nessa realidade, a pedagogia tem pouco a fazer, a menos que se contente em servir como tecnologia manipulatória para instrumentalizar um ensino transmissivo, árido, sem sentido a seus participantes.

Paulo Freire inaugurou uma outra lógica com sua Pedagogia do Oprimido: ou seja, se há pedagogia, esta há de estar voltada a processos de formação, de conscientização e de emancipação e ao lado dos esfarrapados da vida.

Para aprender o aluno precisa se fazer sujeito, cobrir-se de humanidade e construir sentidos: fazer-se um sujeito que se vê no mundo e que pode dizer-se autor desse mundo. Ensinou-nos Paulo Freire: despersonalizados, somos oprimidos e mudos!

Paulo Freire também realça que para fazer-se pedagogo é fundamental estar no mundo, com o mundo e fazer de sua prática aquilo que consolida sua teoria e de sua teoria o que continuamente reajusta e concretiza a prática.

Mais uma vez, quero realçar que a racionalidade pedagógica requer a práxis da reflexão; do diálogo e da politicidade (ser e estar no mundo conscientemente) e que esta racionalidade tem sido posta de lado no mundo contemporâneo. Nosso mundo tem se afastado dessa racionalidade crítica em prol da lógica neoliberal que simplifica e tecnifica os processos 
pedagógicos, despersonalizando os sujeitos da prática, quer alunos, quer professores. Considero isso um crime à nossa humanidade, à nossa possibilidade de ser-mais.

Paulo Freire nos ajuda a olhar os problemas postos no mundo contemporâneo, invadido por exclusões cada vez maiores; com desigualdades e contradições que expõem a dignidade dos sujeitos sociais: uma educação emancipatória, tecida por uma pedagogia crítica, pode formar sujeitos que compreendem essa contínua circularidade entre dominação e opressão e que sejam capazes de coletivamente, buscar e lutar por novas relações de poder, mais justas e solidárias.

Uma educação crítica, pautada no diálogo e na problematização da realidade pode oferecer novos caminhos entre inúmeras culturas, etnias e lugares sociais, referendando um novo princípio de educação democrática, com base na ampliação e na consolidação dos processos emancipatórios e críticos.

Acredito que precisamos, nós educadores, de práticas de resistência, moldadas pelos princípios e práticas da pedagogia crítica. Precisamos voltar a acreditar que um novo mundo é possível, onde as práticas de solidariedade e participação coletiva sejam as protagonistas de novas relações pedagógicas.

\section{REFERÊNCIAS}

ALTHUSSER, Louis. Ideologia e aparelhos ideológicos de estado. Lisboa: Presença, 1970.

ANDRADE FILHO, Bento. Pedagogia: estudo filosófico-científico da educação. São Paulo: Saraiva, 1957.

ANÍSIO, Pedro M. Tratado de pedagogia. Rio de Janeiro: Civilização Brasileira, 1934.

AZEVEDO, Fernando. A educação e seus problemas. São Paulo: Companhia Editora Nacional, 1937.

BAUDELOT, C.; ESTABELET, R. L'école capitaliste en France. Paris: Maspero, 1971.

BOURDIEU, P.; PASSERON, J. C. A reprodução: elementos para uma teoria do sistema de ensino. Rio de Janeiro: Francisco Alves, 1975.

CAMBI, Franco. História da Pedagogia. São Paulo: UNESP, 1999.

CHARLOT, Bernard. Du Rapport au Savoir: éléments pour une théorie. Paris: Economica, 1997.

DEWEY, J. La ciência de la education. Buenos Aires: Losada, 1976. 
EZPELETA, J.; ROCKWELL, E. La escuela: un relato de un processo de construcción inconcluso. In: MADEIRA, F.R. e MELLO, G. N. Educação na América Latina: os modelos teóricos e a realidade social. São Paulo: Cortez, 1985.

FRANCO, Maria Amélia do Rosário Santoro. A pedagogia como ciência da educação: entre epistemologia e prática. 2001. 257 f. Tese (Doutorado - Faculdade de Educação) Universidade de São Paulo: São Paulo.

. Pedagogia como ciência da educação. 3. ed. Campinas: Cortez, 2013.

Pedagogia e prática docente. 2. ed. São Paulo: Cortez, 2012.

. Verbete: antipedagogismo. REVEC: Revista de Estudos Culturais, São Paulo, v.2, p.99-110. 2015.

FREIRE, Paulo. Educação como prática da liberdade. Rio de Janeiro: Paz e Terra, 1976.

. A Pedagogia do oprimido. Rio de Janeiro: Paz e Terra, 1975.

. Conscientização. São Paulo: Cortez, 1984.

. Política e educação. São Paulo: Cortez.1993.

Terra, 1999.

Pedagogia da autonomia: saberes necessários à prática educativa. São Paulo: Paz e

FREITAG, Bárbara. Escola, Estado e Sociedade. São Paulo: Moraes, 1984.

GENTILI, P.A.A. O discurso da "qualidade" como nova retórica conservadora, no campo educacional. In: GENTILI, P.A.A. \& SILVA, T.T. (org.) Neoliberalismo, qualidade total e educação. 2. ed. Petrópolis: Vozes, 1995

GERHARDT, Heinz-Peter. Paulo Freire. In: GADOTTI, M. (Org.). Paulo Freire: uma biobibliografia. São Paulo, Brasília: Cortez, Instituto Paulo Freire, UNESCO, 1996.

GRAMSCI, Antonio. Os intelectuais e a organização da cultura. Rio de Janeiro: Civilização Brasileira, 1973.

GIROUX, H. Theory and resistance in education: a pedagogy for the opposition. Amherst, London: Begin \&Garvey, 1983.

HABERMAS, Jürgen. Connaissance et intérêt. Paris: Gallimard, 1984.

HERBART, Johan F. Pedagogia general derivada del fin de la educación. Madrid: Ediciones de La Lectura, s/d.

KLAFKI, W. Los fundamentos de una didáctica crítico-constructiva. Revista de Educación, Madri, n. 280, p.37-79, 1986. 
KINCHELOE, Joe L. A formação do professor como compromisso político: mapeando o pós-moderno. Porto Alegre: Artes Médicas, 1997.

KOSIK, K. Dialética do concreto. 6. ed. Rio de Janeiro: Paz e Terra, 1995.

LIBÂNEO, J.C. Pedagogia e pedagogos: para quê? São Paulo: Cortez, 1998.

MARX, K.; ENGELS, F. A ideologia alemã: teses sobre Feuerbach. São Paulo: Moraes, 1994.

MOUNIER, Emmanuel. O personalismo. Lisboa: Livraria Moraes, 1964.

MORROW, R.; TORRES, C. A. Jurgen Habermas. Paulo Freire e pedagogia crítica: novas orientações para a educação comparada. Educação, Sociedade e Culturas, Centro de Investigação e Intervenção Educativas (CIIE) da Universidade do Porto, Portugal, n. 10, p. 123-155, 1998.

POULANTZAS, Nicos. A escola em questão. Tempo Brasileiro. n. 35. Rio de Janeiro: Editora Universitária, 1973.

SAVIANI, D. Escola e democracia. São Paulo: Cortez, 1983.

SCHMIED-KOWARZIK, W. Pedagogia dialética - de Aristóteles a Paulo Freire. São Paulo: Brasiliense, 1983.

THERRIE N, J. Os saberes da racionalidade pedagógica na sociedade contemporânea.

Educativa, Goiânia, v. 9, n. 1, p. 67-81, jan./jun. 2006.

TORRES, Carlos Alberto. A práxis educativa de Paulo Freire. São Paulo: Loyola, 1979. Paulo Freire: education y conscientización. Salamanca: Sigueme, 1980. 